\title{
Structural compressibility in 3D printed abrasion protection structures
}

\author{
Sarah Lysann Zedler ${ }^{1 *}$ \\ ${ }^{1}$ Sächsisches Textilforschungsinstitut e. V., Chemnitz, Germany \\ ${ }^{*}$ Corresponding author E-mail address: sarah.lysann.zedler@stfi.de
}

\section{INFO}

CDAPT, ISSN: 2701-939X

Peer reviewed article

2020, Vol.1, Nr. 2, pp. 3-11

DOI:10.25367/cdatp.2020.1.p3-11

Received: 28 April 2020

Accepted: 10 June 2020

Available online: 22 September 2020

\section{Keywords}

textiles,

3D printing,

functionalization

abrasion resistance,

compressibility

\begin{abstract}
Abrasion protection in exposed areas is a common method of extending the life cycle of textile products. To achieve sufficient abrasion resistance, the textile products are usually coated or partially printed with hard products. But hard materials lead to stiffening and can have a negative effect on the haptics. The aim of this study is the application of abrasion-resistant and compressible print patterns directly to textile substrates by $3 D$ printing. The compressibility is achieved by the inner structure, which, in contrast to conventional coatings and screen prints, is not $100 \%$ filled. In the investigations, four thermoplastic materials were tested for their abrasion resistance and compressible properties. Fabrics made of cotton or polyester/cotton blends were used as textile substrates. Different approaches were taken to create the structures, some of which can only be realized using $3 D$ printing technology. The abrasion resistance of the substrates could be increased from 50 abrasion cycles to over 8,000 cycles with the help of the 3D printed patterns. It was possible to print $3 D$ structures that could be compressed in thickness by up to $53 \%$. The combination of both properties, abrasion resistance and compressibility, can be used for new types of individual products with good wearing comfort and functionality that meet the requirements, especially in the areas of functional, protective and sports clothing.
\end{abstract}

(C) 2020 The authors. Published by CDAPT.

This is an open access article under the CC BY-NC-ND license https://creativecommons.org/licenses/ peer-review under responsibility of the scientific committee of the CDAPT.

\section{Introduction}

Textile products are additionally protected from abrasion and wear in exposed areas to increase the durability of the textile. For this purpose, durable raw materials or all-over coatings as well as partial print layers can be used. Abrasion protection by patches results in seams that are not always desired. With allover coatings there is a risk that the flexibility and breathability of the textile will be reduced too much. Partial print layers or patterns reduce the flexibility of the textile less. However, hard materials are often used which reduce the wearing comfort under pressure/stress on the structures. 
Currently, screen printing is mainly used for the application of partial, functional structures on textiles, as it allows the use of higher viscosity and filled printing materials [1-4]. The disadvantage of screen printing is that separate printing stencils must be produced for each design. This requirement increases both the set-up times and the costs for the production and storage of the stencils. With digital printing processes, the disadvantage of stencil production does not exist, but inkjet printing is used for color printing and conductive structures and not yet for commercial functional printing on textiles because low-viscosity inks are required $[3,5,6]$.

3D printing combines the advantages of digital technologies and screen printing. The production process of stencils is no longer necessary. Design changes are therefore possible without long set-up times. In addition to the initial development of using different 3D printing processes for textile and clothing production $[7,8]$, there are increasing ambitions to functionalize textile substrates using $3 D$ printing.

Fused Layer Modelling (FLM) is used for this purpose, in which thermoplastic materials are fed as a filament to a heated nozzle, melted in it and then deposited in layers with the correct contours [9]. In previous studies, the focus was on adhesion forces between printed material and textile substrates, because sufficient adhesion is required for a successful functionalization [10-14].

Furthermore, 3D printed structures have been used to influence physical properties of textiles, such as flexural strength [14], fabric draping [15] or abrasion resistance against wool fabric [16-20].

So far, no studies have been published on the production of very high abrasion resistance in combination with compressible structures on textiles. The aim of this study is the production of abrasion-resistant and compressible print patterns. The abrasion resistance should be effective against sandpaper instead of wool fabric. The compressibility is to be created by different structures inside.

\section{Materials and methods}

\subsection{Materials}

Fabrics from the sector of work and protective clothing made of cotton (CO) or polyester/cotton (PES/CO) blends with twill weave were used as textile substrates. Their properties, like basis weight (DIN EN 12127), number of threads (DIN EN 1049-2) and thickness (DIN EN ISO 5084), were tested according to international standards and are listed in Table 1.

Table 1. Textile properties.

\begin{tabular}{|c|c|c|c|}
\hline Textile properties & T1 & T2 & T3 \\
\hline material composition & $100 \% \mathrm{CO}$ & $100 \% \mathrm{CO}$ & $65 \%$ PES / $35 \%$ CO \\
\hline description of finishing & finished, shrunk & $\begin{array}{l}\text { flame retardant } \\
\text { impregnated, shrunk }\end{array}$ & finished \\
\hline basis weight $\left(\mathrm{g} / \mathrm{m}^{2}\right)$ & $302.67 \pm 2.50$ & $294.99 \pm 2.18$ & $297.88 \pm 0.98$ \\
\hline number of warp threads $(1 / \mathrm{cm})$ & $36.97 \pm 0.217$ & $29.70 \pm 0.075$ & $41.70 \pm 0.274$ \\
\hline number of weft threads $(1 / \mathrm{cm})$ & $24.36 \pm 0.06$ & $19.20 \pm 0.00$ & $22.74 \pm 0.06$ \\
\hline thickness $(\mathrm{mm})$ & $0.55 \pm 0.01$ & $0.53 \pm 0.01$ & $0.52 \pm 0.01$ \\
\hline
\end{tabular}

Four different 3D printing filaments with a Shore hardness of $\leq 95 \mathrm{~A}$ were used as printing materials which parameters are listed in Table 2.

Table 2. Parameters of printing material.

\begin{tabular}{llll}
\hline Print polymer & Chemical basis & Shore Hardness & Printing Temperature $\left({ }^{\circ} \mathbf{C}\right)$ \\
\hline P1 & polylactic acid (PLA) & $92 \mathrm{~A}$ & 210 \\
P2 & co-polyester (Co-PES) & $95 \mathrm{~A}$ & 220 \\
P3 & thermoplastic elastomer (TPE) & $92 \mathrm{~A}$ & 170 \\
P4 & thermoplastic polyurethane (TPU) & $85 \mathrm{~A}$ & 235 \\
\hline
\end{tabular}

The system used for the project was the 3D material application system of CVM GmbH (Neukirchen, Germany), which is installed at the Saxon Textile Research Institute (Chemnitz, Germany). The integrated 
FLM module was used with a nozzle diameter of $0.4 \mathrm{~mm}$. The textile substrate was clamped with the clamping possibilities available on the system (Fig. 1).

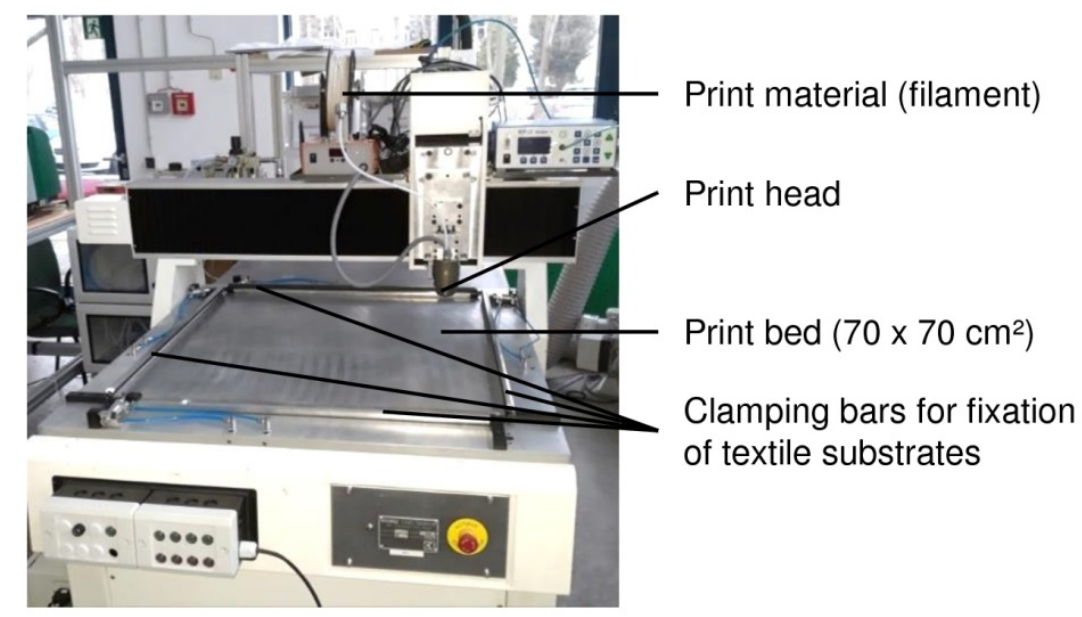

Fig. 1 3D material application system with clamping bars for fixation of textile substrates.

\subsection{Methods}

For the printing tests, 3D structures were created using Rhinoceros 6 and included Grasshopper (McNeel Europe S.L., Barcelona, Spain) as CAD software and then converted into machine-specific data for printing using Repetier-Host (Hot-world GmbH \& Co. KG, Willich, Germany) as slicer software.

The study is divided into three parts: Part 1 is the development of the abrasion resistant structures which include data generation, printing and testing. The raw materials, pure printed layers and the printed specimens were tested for their resistance to abrasion in accordance to the standard DIN EN 388, 6.1. Two specimens each with a diameter of $38 \mathrm{~mm}$ were clamped in specimen holders and rubbed against sandpaper (Klingspor PL31B, grit 180). The minimum number of abrasion cycles at breakthrough, i. e. when holes are formed, is relevant for the evaluation of the material according to the performance levels 1 to 4 specified in the standard. The best possible rating is performance level 4 , which is achieved when no breakthrough has occurred after 8,000 cycles. The lower value from the abrasion test was used for the evaluation.

Part 2 is the investigation of compressible properties which was performed parallel to abrasion tests. For testing the compressible properties, specimens with a square base area of $70 \times 70 \mathrm{~mm}^{2}$ were produced without a textile substrate. In accordance to DIN EN ISO 9863-1, the thicknesses $t_{p_{i}}$ of the specimens were determined under the specified pressures of $\mathrm{p}_{1}=2 \mathrm{kPa}, \mathrm{p}_{2}=20 \mathrm{kPa}, \mathrm{p}_{3}=200 \mathrm{kPa}$. With these values the compressibility $\mathrm{C}$ according to equation (1) were calculated.

$\mathrm{C}=\frac{\mathrm{t}_{\mathrm{p}_{\mathrm{i}}}-\mathrm{t}_{\mathrm{p}_{1}}}{\mathrm{t}_{\mathrm{p}_{1}}} \cdot 100 \%$

In addition, the thicknesses were measured after a recovery period of $3 \mathrm{~min}$ at the pressure of $2 \mathrm{kPa}\left(\mathrm{p}_{1}\right.$, $)$ to get the regeneration $\mathrm{R}$ according to equation (2).

$\mathrm{R}=\frac{\mathrm{t}_{\mathrm{p}_{1 \prime}}}{\mathrm{t}_{\mathrm{p}_{1}}} \cdot 100 \%$

Part 3 is the combination of the best results out of abrasion resistance and compressible properties which was performed after the two previous parts. The 3D printing parameters which were used in every part are listed in Table 3. 
Table 3. 3D printing parameters.

\begin{tabular}{|c|c|c|}
\hline Parameters & Part 1 (abrasion) & Part 2 (compressibility) \\
\hline layer height $(\mathrm{mm})$ & 0.2 & 0.2 \\
\hline extrusion width $(\mathrm{mm})$ & 0.4 & 0.4 \\
\hline printing bed temperature $\left({ }^{\circ} \mathrm{C}\right)$ & 35 & 35 \\
\hline fill pattern & rectilinear & rectilinear \\
\hline fill density (\%) & 100 & 100 \\
\hline exception: varying fill density FD (\%) & - & $\mathrm{FD}_{1}=5, \mathrm{FD}_{2}=10, \mathrm{FD}_{3}=20$ \\
\hline
\end{tabular}

\section{Results}

\subsection{Abrasion resistance}

The textile fabrics are destroyed after 50 (T1, T2) and 100 (T3) abrasion cycles which is less than performance level 1. For further abrasion tests $\mathrm{T} 1$ was used because it is the fabric with lowest abrasion resistance. The printing materials were tested individually as all-over print layers. A breakthrough in the printed layers were found after $\mathrm{P} 1=4,400$ cycles, $\mathrm{P} 2=3,700$ cycles and $\mathrm{P} 3=5,500$ cycles which is defined as performance level 3. P4 shows no perforation in the printed layer after 8,000 abrasion cycles (performance level 4). Because of their good abrasion resistance and printing properties, polymers P1 and P4 were used for the further abrasion tests. A total of 16 abrasion protection structures were constructed by factorial experimental design. The four factors with their levels are listed in Table 4.

Table 4. Factors and their levels for the generated abrasion resistant structures.

\begin{tabular}{lll}
\hline Factor & Level $\mathbf{1}$ & Level $\mathbf{2}$ \\
\hline 1) geometry & geometry A (diamonds) & geometry B (Voronoi structures) \\
2) geometry size & big geometries & small geometries \\
$\quad$ for geometry A: side length a $(\mathrm{mm})$ & $\mathrm{a}_{1}=15$ & $\mathrm{a}_{2}=10$ \\
$\quad$ for geometry B: number of base points $\mathrm{x}$ & $\mathrm{x}_{1}=10$ & $\mathrm{x}_{2}=20$ \\
3) area coverage ratio CR (\%) & $\mathrm{CR}_{1}=60$ & $\mathrm{CR}_{2}=80$ \\
4) print height $\mathrm{H}(\mathrm{mm})$ & $\mathrm{H}_{\text {const }}=0.4$ & $\mathrm{H}_{\mathrm{var}}=\{0.4,0.6,0.8\}$ \\
\hline
\end{tabular}

For the basic geometry two different approaches were followed. Geometry A consists of a uniform pattern based on rounded diamonds with a rounding radius $\mathrm{r}=2.5 \mathrm{~mm}$. The diamond size was varied by the side length a. Geometry B consists of algorithm based Voronoi structures. Thereby a rectangle is provided with base points. The size of the Voronoi cells was determined by the number of base points $x$ (Fig. 2a). The structures were created once with a constant print height $\mathrm{H}_{\text {const }}=0.4 \mathrm{~mm}$. In addition, an algorithm was used to set a variable print height of $\mathrm{H}_{\mathrm{var}}=\{0.4 \mathrm{~mm}, 0.6 \mathrm{~mm}, 0.8 \mathrm{~mm}\}$ depending on the center of the test surface. The centre point corresponds to the maximum height (Fig. 2b, c). A sample of the printed specimens out of P4 on T1 is shown in Figure 2d. 

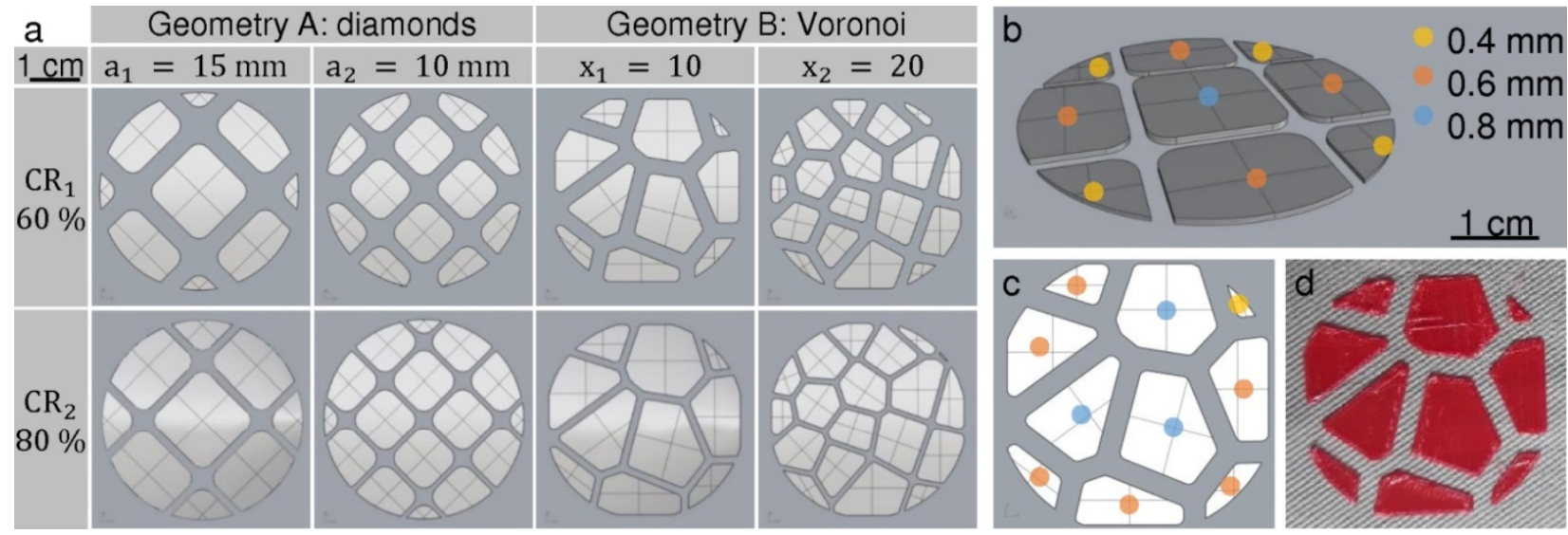

Fig. 2 Abrasion protection structures: (a) plan view of the test geometries; (b) perspective view of structure with variable height (color-coded); (c) plan view of structure with variable height (color-coded); (d) printed sample with Voronoi geometry.

Five parameter combinations have reached the maximum performance level 4 (Figure 3). These combinations were manufactured with $\mathrm{P} 4$ and variable print height. The print height is a very important parameter to improve abrasion resistance. It is not necessary to increase the print height uniformly over the entire surface. As the results show, it is sufficient to strengthen the center of abrasion protection structures. In this case, the 3D printing process can show its advantages when printing variable heights without the need for different stencils. The figure also shows that the area coverage ratio is another influential parameter. As expected, higher area coverage results in better abrasion resistance. In most cases, a variable print height leads to the same improvement as increasing area coverage ratio. These results mean that both parameters can be used for improvements depending on the printing time. In contrast, the geometry as well as geometry size has less influence on the abrasion resistance.

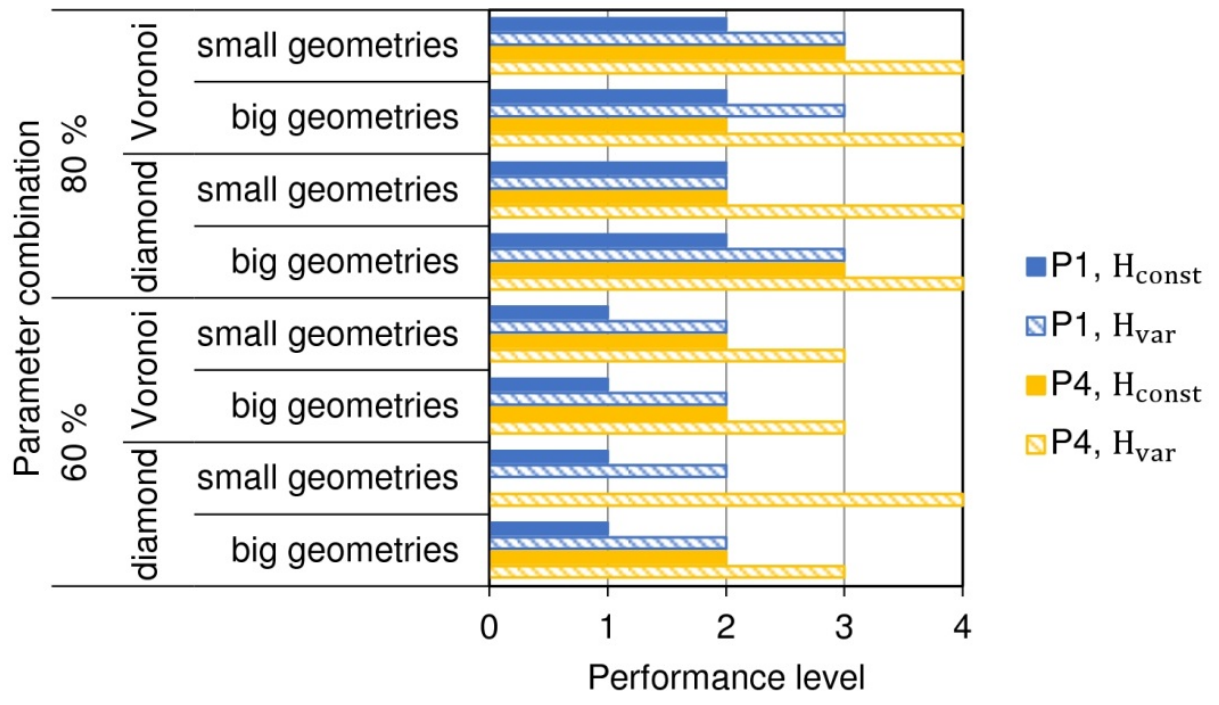

Fig. 3 Achieved performance levels of the different parameter combinations grouped by material and print height.

\subsection{Compressible properties}

The compressible structures were created using two different design approaches. On the one hand, the fill density FD of a cuboid was varied within the slicer software: $\mathrm{FD}_{1}=5 \%, \mathrm{FD}_{2}=10 \%$ and $\mathrm{FD}_{3}=20 \%$. In each case nine layers with the corresponding fill density and additionally completely filled base and top layers were set. On the other hand, the closed base and top layers were connected in the second approach by constructed dampening bars. These bars were created in CAD software with an overhang angle of $\alpha=$ $45^{\circ}$ and a varying number of turns $\mathrm{n}$ (Figure 4). A single bent bar (one zigzag) corresponds to one turn $(\mathrm{n}=1)$. 


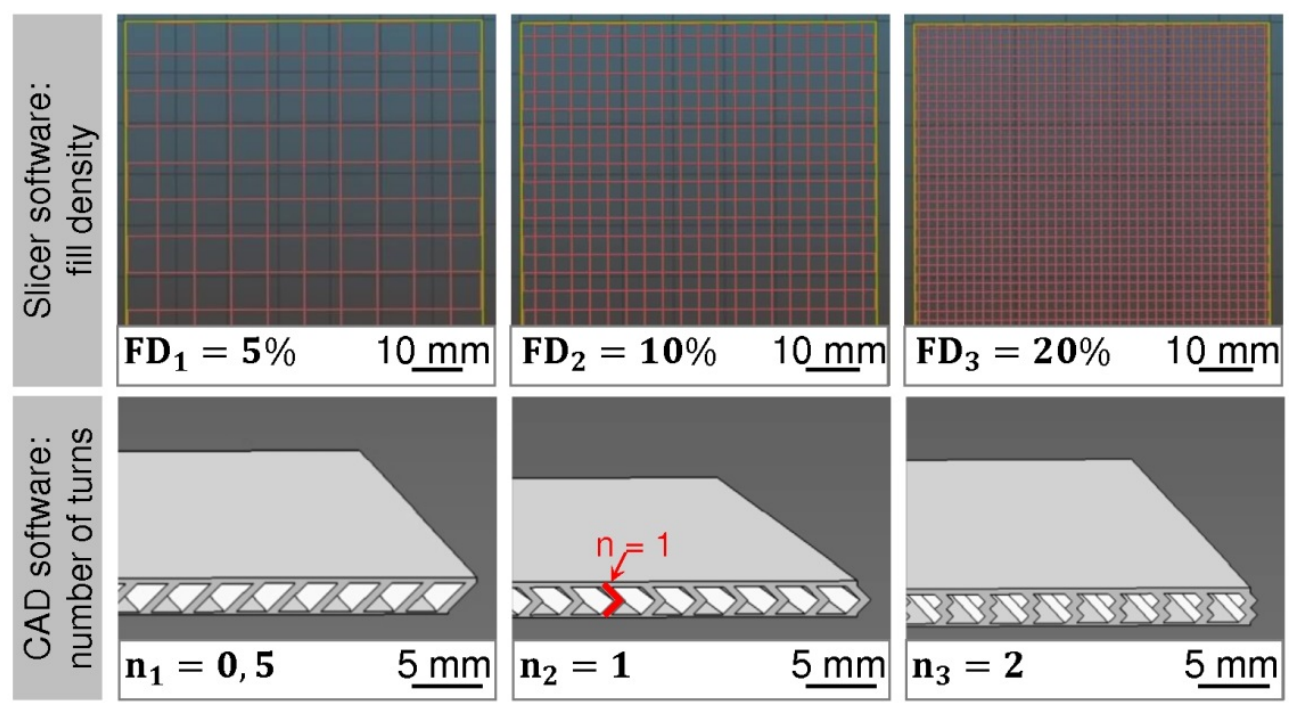

Fig. 4 Internal structures created by varying fill density in slicer software (top) and structures created in CAD software with dampening bars depending on the number of turns $n$ (bottom).

The compressibility $\mathrm{C}$ depends on the printing material, the test pressure and the geometry of the inner structure (Figure 5). Polymer P4, which has the lowest Shore hardness, is more compressible. At a test pressure of $20 \mathrm{kPa}$, the compressibility hardly differs between the different geometries. For specimens printed with P1 and P2 compressibility is lower if the fill density is varied instead of the number of turns. For samples made of P4 it is the other way around. At a fill density of $5 \%$, the compressibility of specimens printed with P4 increases clearly up to $17 \%$. It was not possible to print samples out of P3 with fill density of $5 \%$ because of printing process purposes. The printed strands fell into the cavities. That is why the top layers were too uneven to get tested. At a test pressure of $200 \mathrm{kPa}$ the compressibility values are significantly higher. The variation of the fill density leads to differently strong rising values, while the compressibility is increased more evenly by changing the number of turns. The highest compressibility is $53 \%$, which is reached by $\mathrm{P} 4$ samples with $\mathrm{FD}_{1}=5 \%$.

The quality and durability of the compressible structures were analyzed by regeneration $\mathrm{R}$ (Figure 6). The structures of all polymers except $\mathrm{P} 1$ have regenerated with values of $97.9 \% \leq \mathrm{R} \leq 100.0 \%$. The samples made of $\mathrm{P} 1$ contain regeneration values of $83.6 \% \leq \mathrm{R} \leq 100.0 \%$. The minimum regeneration occurred at $\mathrm{FD}_{1}=5 \%$. This significantly less regeneration indicates a damage of the inner structure of the samples of $\mathrm{P} 1$ at this fill density. This conclusion is supported by crackling noises when the samples are compressed after the test.

Overall, both design approaches are suitable for creating cavities to achieve structural compressibility in addition to the material compressibility. The first design approach with the fill density has less engineering effort. Thus the fill density can be easily changed in slicer software. But this parameter cannot be varied within a single object. This means, for example, that the object has the same fill density in the middle as at the borders.

The second design approach using the number of turns or other designs generated in CAD software rather than slicer software is much more customizable. Therefore, the second approach can be used to create a variable internal structure depending on the required compressibility. 


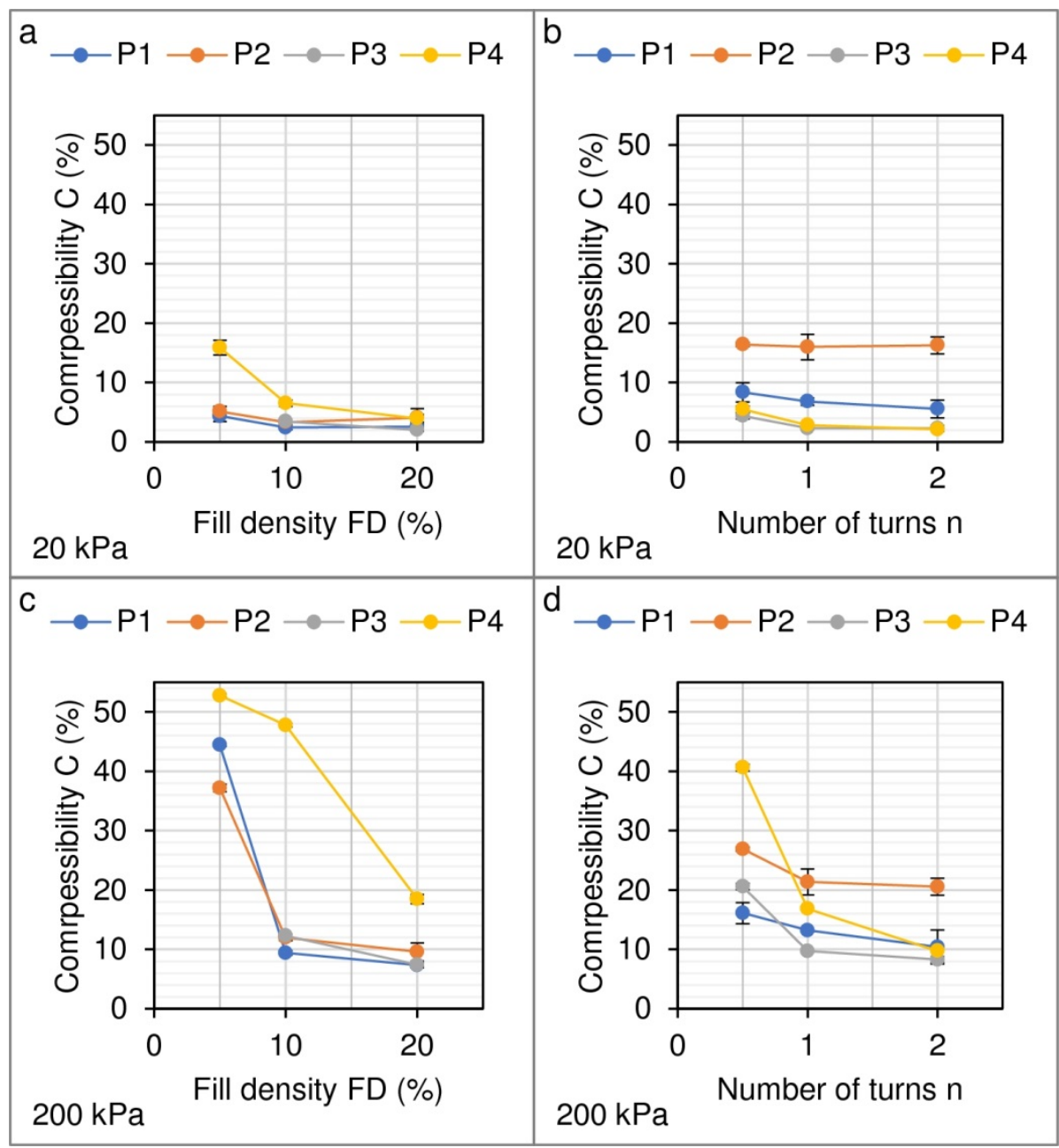

Fig. 5 Compressibility $C$ depending on material with (a) test pressure of $20 \mathrm{kPa}$ and varying fill density; (b) test pressure of $20 \mathrm{kPa}$ and varying number of turns; (c) test pressure of $200 \mathrm{kPa}$ and varying fill density; (d) test pressure of $200 \mathrm{kPa}$ and varying number of turns.

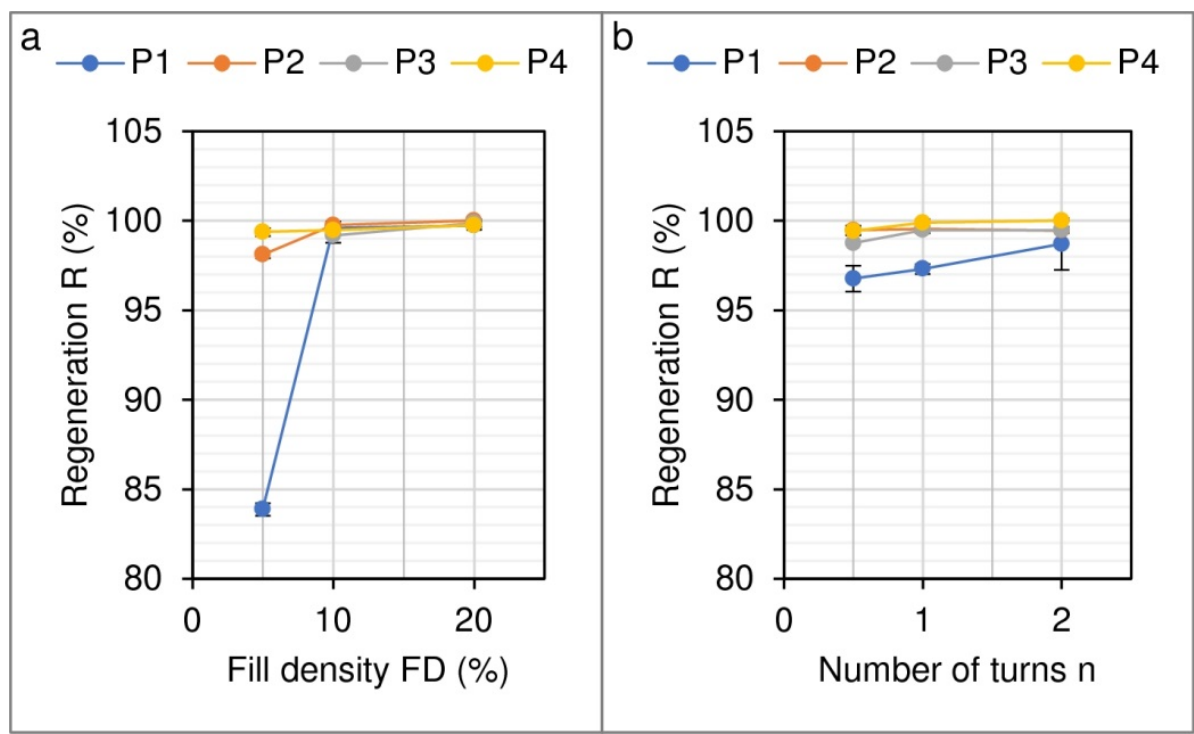

Fig. 6 Regeneration R depending on material and (a) fill density; (b) number of turns. 


\subsection{Combination of abrasion-resistant and compressible properties}

Finally, the best results of the previous structures were selected to produce 3D prints with abrasion resistance and compressibility. The combination of both properties can be used to create novel individual products with good wearing comfort and functionality in line with requirements. Figure 7 shows a printed sample made of $\mathrm{P} 4$ on $\mathrm{T} 1$ with abrasion-resistant structure out of diamonds with an area coverage ratio of $80 \%$ and variable print height of $h_{v a r}=\{0.4 \mathrm{~mm}, 1.2 \mathrm{~mm}, 2.0 \mathrm{~mm}, 2.6 \mathrm{~mm}\}$. The print height is higher than in previous abrasion tests because the dampening bars with $n=0.5$ were included as internal structure for compressible properties. The combination of these properties can be used in protective structures in functional and sports clothing.
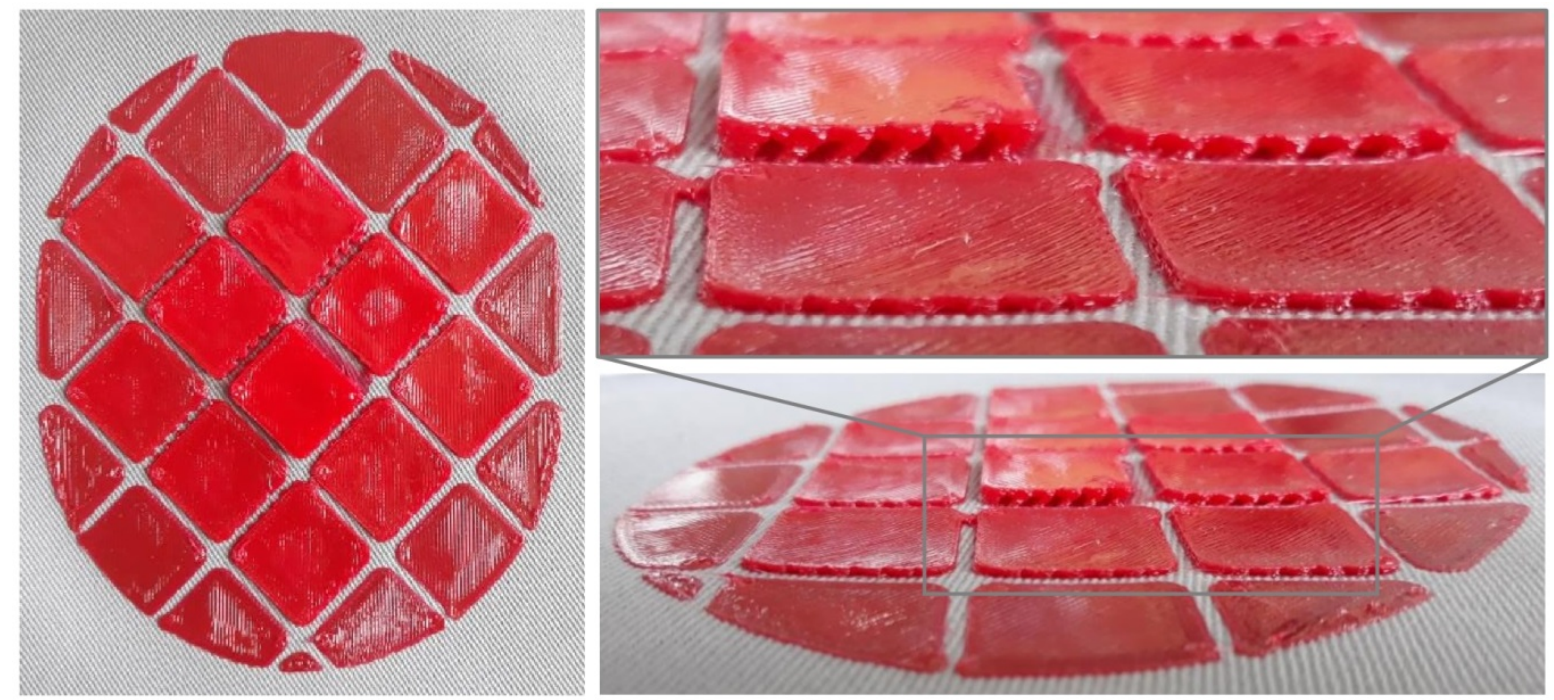

Fig. 7 Printed sample of diamond structures with variable print height for abrasion resistance combined with dampening bars for compressible properties.

\section{Conclusions}

Using 3D printing, structures were created that increase the abrasion resistance of the examined cotton fabric from 50 abrasion cycles to over 8,000 cycles. The printing material, the print height and the area coverage ratio are the most important parameters to improve the abrasion resistance. It is sufficient to increase the print height at the center of the abrasion protection structure. Both design parameters, print height and area coverage ratio, can be used for improvements depending on the printing time. The geometry as well as the geometry size has shown less influence on the abrasion resistance.

Materials with a Shore hardness of $\leq 95 \mathrm{~A}$ were used. By adapting the internal structure of the threedimensional designs, it is possible to achieve a compressibility of up to $53 \%$. While varying the fill density has less engineering effort, generating specific inner structures in CAD software is much more customizable. Therefore, the second approach can be used to create a variable internal structure depending on the required compressibility. When selecting the appropriate structure, the ability to regenerate must also be taken into account because damages of the internal structure at $\mathrm{FD}_{1}=5 \%$ for P1 specimens were detected.

The results contribute to the extension of the application possibilities of 3D printing on textile substrates. The combination of both properties, abrasion resistance and compressibility, can be used for new types of individual products with good wearing comfort and functionality that meet the requirements. Thus, these results are relevant especially for the areas of functional, protective and sports clothing. 


\section{Acknowledgements}

We acknowledge the support of the Federal Ministry of Economics and Energy for the funding of the project (Reg.-No. 49MF170026) within the funding programme "FuE-Förderung gemeinnütziger externer Industrieforschungseinrichtungen - Innovationskompetenz (INNO-KOM) - Modul: Marktorientierte Forschung und Entwicklung (MF)."

\section{References}

[1] Martinez I.; Mao, C.-X.; Vital, D.; Shahariar, H.; Werner, D. H.; Jur, J. S.; Bhardwaj, S. Compact, Low-Profile and Robust Textile Antennas With Improved Bandwidth for Easy Garment Integration. IEEE Access, 2020, 8, pp. 77490-77500. DOI: 10.1109/ACCESS.2020.2989260.

[2] Suikkola, J.; Björninen, T.; Mosallaei, M.; Kankkunen, T.; Iso-Ketola, P.; Ukkonen, L.; Vanhala, J.; Mäntysalo, M. Screen-Printing Fabrication and Characterization of Stretchable Electronics. Sci. Rep., 2016, 6 (25784). DOI: 10.1038/srep25784.

[3] Zeng, W., Shu, L., Li, Q., Chen, S., Wang, F., Tao, X.-M. Fiber-Based Wearable Electronics: A Review of Materials, Fabrication, Devices, and Applications. Adv. Mater, 2014, 26 (31), pp. 5310-5336. DOI: 10.1002/adma.201400633.

[4] Stančić, M.; Kasikovic, N.; Novaković, D.; Dojcinovic, I.; Vladić, G.; Dragić, M. The influence of washing treatment on screen printed textile substrates. TEKSTIL ve KONFEKSIYON, 2014, 24 (1), pp. 96- 104.

[5] Tawiah, B.; Howard, E. K.; Asinyo, B. K. The Chemistry Of Inkjet Inks For Digital Textile Printing - Review. BEST: IJMITE, 2016, 4 (5), pp. 61-78.

[6] Chauraya, A.; Whittow, W. G.; Vardaxoglou, J. C.; Li, Y.; Torah, R.; Yang, K.; Beeby, S.; Tudor, J. Inkjet Printed Dipole Antennas on Textiles for Wearable Communications. IET Microw. Antennas Propag., 2013, 7 (9), pp.760767. DOI: 10.1049/iet-map.2013.0076.

[7] Beecroft, M. 3D printing of weft knitted textile based structures by selective laser sintering of nylon powder. Global Conference on Polymer and Composite Materials (PCM 2016), IOP Conf. Ser.: Mater. Sci. Eng., 2016, 137, pp. 01-07. DOI: 10.1088/1757-899X/137/1/012017.

[8] Beecroft, M. Digital interlooping: 3D printing of weft-knitted textile based tubular structures using selective laser sintering of nylon powder. Int. J. Fash. Des., Technol. Educ., 2019, 12 (2), pp. 218-224. DOI: $10.1080 / 17543266.2019 .1573269$.

[9] VDI-Gesellschaft Produktion und Logistik. VDI3405:2014-12 - Additive manufacturing processes, rapid manufacturing - Basics, definitions, processes. Beuth Verlag: Berlin, Germany, 2014; pp. 12-13.

[10] Deleersnyder, K. 3D Printing on textiles - new tool for customized fabrics. 3F-Talks: Functional Fibres and Films, Aachen, Germany, 29.04.2016.

[11] Korger, M.; Bergschneider, J.; Lutz, M.; Mahltig, B.; Finsterbusch, K.; Rabe, M. Possible Applications of 3D Printing Technology on Textile Substrates. 48th Conference of the International Federation of Knitting Technologists (IFKT), IOP Conf. Ser.: Mater. Sci. Eng., 2016, 141. DOI:10.1088/1757-899X/141/1/012011

[12] Döpke, C., Grimmelsmann, N., Ehrmann, A. 3D-Druck auf Gestricken. Melliand Textilberichte, 2016, 97 (4), pp. 195-196.

[13] Hashemi Sanatgar, R.; Campagne, C.; Nierstrasz, V. Investigation of the adhesion properties of direct 3D printing of polymers and nanocomposites on textiles: Effect of FDM printing process parameters. Appl. Surf. Sci., 2017, 403, pp. 551-563. DOI: 10.1016/j.apsusc.2017.01.112.

[14] Göbel, S. L.; Siegel, F. Changing Physical Properties of Textiles by 3D Printing. Proceedings of the Printing Future Days 2017, Chemnitz, Germany, 04.-06.10.2017; Verlag für Wissenschaft und Bildung: Berlin, Germany, 2017; pp. 171-175.

[15] Ehrmann, A.; Fafenrot, S.; Grimmelsmann, N. Beeinflussung des Warenfalls durch 3D-Aufdruck. TEXTILplus, 2017, 1-2; pp. 21-23.

[16] Sabantina, L.; Kinzel, F.; Ehrmann, A.; Finsterbusch, K. Combining 3D printed forms with textile structures mechanical and geometrical properties of multi-material systems. IOP Conf. Ser.: Mater. Sci. Eng., 2015, 87. DOI:10.1088/1757-899X/87/1/012005

[17] Korger, M.; Bergschneider, J.; Neuss, J.; Mahltig, B.; Rabe, M. Additive Manufacturing for Textile Surface Modification. 3F-Talks: Functional Fibres and Films, Aachen, Germany, 29.04.2016.

[18] Bergschneider, J.; Korger, M.; Kyosev, Y.; Lutz, M.; Rabe, M.; Mahltig, B. Textilfunktionalisierung mit 3D-Druck - Echtheiten und Schichtadhäsion. Melliand Textilberichte, 2016, 97 (4), pp. 197-199.

[19] Kreikebaum, E.; Lutz, M.; Doerfel, M.; Finsterbusch, K.; Ehrmann, A.; 3D-Druck von Blindenschrift auf Textil. Technische Textilien, 2017, 60 (2), pp. 92-93.

[20] Sanduloff, S., Korger, M., Glogowsky, A., Meyer, J., Steinem, C., Huysman, S., Ernst, M., Rabe, M. Body contour compatible protectors using 3D printing technology / Körperkonturgerechte Protektoren mittels 3DDrucktechnologie. 58th DORNBIRN-GFC, Dornbirn, Austria,12.09.2019. 